\title{
Conhecimento de Agentes Comunitários de Saúde sobre os instrumentos de coleta de dados do SIAB
}

\author{
Knowledge of Community Health Workers on the SIAB's instruments for data collection
}

Conocimiento de Agentes Comunitarios de Salud sobre los instrumentos de recopilación de datos del SIAB

\section{Aline Pinto de Lima', Áurea Christina de Paula Corrêa', Quéli Cristina de Oliveira"}

\author{
' Universidade Federal de Mato Grosso, Faculdade de Enfermagem, \\ Programa de Pós-Graduação em enfermagem. Cuiabá-MT, Brasil. \\ "Secretaria de Estado da Saúde de Mato Grosso. Cuiabá-MT, Brasil.
}

Submissão 11-11-2010 Aprovação: 21-12-2011

\section{RESUMO}

Este estudo teve como objetivo identificar o conhecimento de Agentes Comunitários de Saúde (ACS) sobre instrumentos/fichas do Sistema de Informação da Atenção Básica (SIAB). Trata-se de um estudo descritivo-exploratório, de abordagem qualitativa, realizado com ACS de duas Unidades de Saúde da Família do município de Cuiabá-MT, utilizando entrevistas semiestruturadas e observação participante para coleta de dados. Para a análise foi utilizada a técnica de análise temática. Emergiram três categorias: 1) reconhecimento dos instrumentos de coleta de dados do SIAB; 2) preenchimento das fichas: dificuldades e dúvidas; 3) resolução das dificuldades e dúvidas. O presente estudo possibilitou a identificação de situações-problema enfrentadas pelos ACS no trabalho com as fichas do SIAB, que demandam ações dos gestores do SUS, como a educação permanente dos profissionais e o aprimoramento da estrutura das fichas/relatórios, adequando-os à realidade local das Unidades de Saúde da Família, por meio de acréscimo ou retirada de dados.

Descritores: Programa Saúde da Família; Sistemas de informação; Atenção primária à saúde.

\begin{abstract}
This study aimed to identify the Community Health Agents' knowledge about the instruments/forms of the Primary Care Information System. This is an exploratory and descriptive study, with qualitative approach, carried out with Community Health Agents of two Family Health Care Units, using semi-structured interviews and participant observation for data collection. The thematic analysis was used to analyze empirical material. Three categories emerged: 1) recognition of each instrument of the Primary Care Information System for data collection; 2) filling in the forms: difficulties and doubts; 3) resolution of difficulties and doubts. The study enabled the identification of problem situations faced by the Community Health Agents in working with the forms of the the Primary Care Information System that require actions of the managers of SUS, such as continuing education for professionals and the improvement of the structure of the forms / reports, adapting them to the local reality of the Family Health Units, by adding or removing data.
\end{abstract}

Key words: Family health program; Information systems; Primary health care.

\section{RESUMEN}

Este estudio tuvo como objetivo identificar los conocimientos de Agentes Comunitarios de Salud (ACS) sobre instrumentos/ fichas del Sistema de Información de Atención Primaria. Estudio exploratorio descriptivo con enfoque cualitativo, efectuado con ACS de dos unidades de salud familiar, mediante entrevistas semiestructuradas y observación participante para recopilación de datos. Para análisis de los datos se utilizó el análisis temático. Se identificarán tres categorías: 1) el reconocimiento de los instrumentos del SIAB; 2) completar los instrumentos: dificultades y dudas; 3) resolución de dificultades y dudas. Este estudio permitió la identificación de situaciones problemáticas que los ACS enfrentan en el trabajo con las fichas del Sistema de Información de Atención Primaria, que requieren acciones de los administradores del SUS, tales como la educación continua para los profesionales y mejorar la estructura de los formularios / informes, la adaptación de la realidad local de las Unidades de Salud de la Familia, mediante la adición o eliminación de datos.

Palabras clave: Programa de salud familiar; Sistemas de información; Atención primaria de salud. 


\section{INTRODUÇÃO}

O exercício da atividade profissional de Agente Comunitário de Saúde (ACS) foi regulamentado pela Lei $n^{\circ} 11.350 / 2006^{(1)}$, que estabeleceu suas atribuições e as diretrizes para o exercício da atividade, possibilitando uma proposição qualitativa de suas ações e evidenciando um perfil profissional que concentra atividades na promoção da saúde, seja pela prevenção de doenças, pela mobilização de recursos e práticas sociais de promoção da vida e cidadania ou mesmo pela orientação de indivíduos, grupos e populações, com características de educação popular em saúde e acompanhamento de famílias ${ }^{(2)}$.

No processo de fortalecimento do Sistema Único de Saúde (SUS), o ACS tem sido um personagem fundamental para a integração dos serviços de saúde da Atenção Primária com a comunidade $^{(3)}$.

$\mathrm{Na}$ equipe multidisciplinar que deve, obrigatoriamente, atuar na Estratégia de Saúde da Família (ESF), modelo criado para reordenar a assistência à saúde no Brasil, essa categoria profissional tem grande importância, atuando como o interlocutor entre as famílias e as equipes ${ }^{(4,5)}$.

O dia a dia do Agente Comunitário de Saúde é permeado por atividades variadas, que vão desde a assistência direta a indivíduos e famílias, apoio educativo e tarefas de cunho burocrático, como o cadastramento familiar ${ }^{(6)}$. Para isso, o ACS realiza o preenchimento de instrumentos para diagnóstico demográfico e sociocultural da comunidade; o registro de nascimentos, óbitos, doenças e outros agravos à saúde para fins exclusivos de controle e planejamento das ações de saúde e visitas domiciliárias periódicas para monitoramento de situações de risco à família ${ }^{(1)}$.

Tais atividades são desenvolvidas, em grande parte, com a utilização do Sistema de Informação da Atenção Básica (SIAB). Trata-se de um programa de sistematização de dados proposto pelo Ministério da Saúde para retratar, por meio de dados e informações, a realidade da área adscrita das Unidades de Saúde da Família (USF). Sua utilização requer o preenchimento de várias fichas de levantamento de dados, sob a responsabilidade de diferentes profissionais da ESF, dentre eles, o $\mathrm{ACS}^{(7)}$.

O momento de realização das visitas domiciliárias é considerado a ocasião apropriada para o preenchimento das seguintes fichas: Ficha A - cadastramento das famílias; Ficha B - acompanhamento de gestantes e pessoas com diabetes, hipertensão, tuberculose ou hipertensão; Ficha C - cópia das informações pertinentes da Caderneta da Criança; e Ficha D registro das atividades diárias do $\mathrm{ACS}^{(3)}$.

$\mathrm{Na}$ Ficha A, os ACS cadastram todas as residências de sua área abrangência. Cumprida esta etapa, realiza uma visita às residências para o preenchimento do cadastro das famílias, levantando dados que permitem identificar as características da população da área, como o número de crianças e gestantes, entre outros ${ }^{(8)}$.

Feito o cadastro, os ACS devem acompanhar as famílias mensalmente. Caso algum morador da área apresente algum agravo ou doença, deve ser acompanhado e informações adicionais inseridas na Ficha B, caso integre um dos grupos estratégicos da ESF, ou na Ficha C, em se tratando de $\operatorname{crianças}^{(7)}$. A Ficha $\mathrm{D}$, de registro de atividades, procedimentos e notificações, é utilizada por todos os profissionais da equipe de saúde, com preenchimento diário e entregue ao final de cada mês na Secretaria Municipal de Saúde ${ }^{(3)}$.

As fichas preenchidas devem permanecer em poder do próprio ACS durante o ano, para o acompanhamento dos usuários da microárea de abrangência. Mensalmente, devem preencher o consolidado desse acompanhamento juntamente com o enfermeiro para o fechamento do Relatório da Situação e Acompanhamento das Famílias na Área/Equipe (SSA2). O ACS responsável pela microárea deve manter consigo uma SSA $2^{(9)}$.

Todas essas fichas devem ser atualizadas sempre que necessário, ou seja, quando da ocorrência de eventos como nascimento ou morte de algum membro da família e inclusão de parente ou agregado no grupo familiar ${ }^{(4)}$.

A coleta de dados é uma das etapas do diagnóstico da comunidade, assim como a análise e interpretação de dados, identificação dos problemas, necessidades, recursos e grupos de risco. Com base nestas informações deve ser realizado o planejamento e a programação das ações priorizadas ${ }^{(10)}$.

A estrutura do Programa de Saúde da Família (PSF) permite à equipe identificar as famílias a serem atendidas, os principais problemas de saúde que acometem a população, os determinantes sociais que geram tais problemas e como a população percebe e enfrenta os problemas referidos. Assim, registrar corretamente os dados, garantindo sua fidedignidade, é uma grande contribuição do ACS no processo de diagnóstico das necessidades de saúde da população(4).

Reconhecendo que o ACS é um personagem-chave na coleta e consolidação desses dados e que pode contribuir decisivamente para o aperfeiçoamento do SIAB e de suas fichas, o presente estudo objetiva identificar o conhecimento que estes profissionais têm acerca desses instrumentos/fichas que utilizam em seu cotidiano de trabalho, identificando as possíveis contribuições que o conhecimento acerca do uso destas instrumentos/fichas pode promover e eventuais dificuldades que possam repercutir na efetivação da proposta da ESF.

\section{MÉTODO}

Trata-se de um estudo descritivo-exploratório de abordagem qualitativa em que os dados foram levantados a partir das técnicas de entrevistas semiestruturadas e observação participante.

A população do estudo foi constituída por ACS de duas USF de um município do estado de Mato Grosso. As unidades foram eleitas de acordo com os seguintes critérios de inclusão: serem localizadas na Regional Norte do município, uma vez que se trata da região definida pela Secretaria Municipal de Saúde para atividades de ensino, pesquisa e extensão da Universidade Federal de Mato Grosso; terem sido implantadas há pelo menos dois anos e contarem com equipes compostas por todos os membros preconizados pela ESF.

Das 13 USF da Regional Norte, dez atendiam aos critérios de inclusão estabelecidos, porém somente quatro dispunham de suporte tecnológico (computador) para manter dados informatizados. Utilizou-se a amostra aleatória simples para definir 
as duas unidades onde o estudo seria realizado, sendo que uma deveria dispor de suporte tecnológico para utilização do SIAB secundário (USF 1) e outra que não dispusesse de tal recurso (USF 2), com vistas a identificar possíveis diferenças quanto à utilização do SIAB.

Para a realização das entrevistas semiestruturadas com os ACS foi utilizado um roteiro composto por questões acerca das fichas do SIAB utilizadas em seu cotidiano de trabalho; a existência ou não de dificuldades no preenchimento e os meios que utilizam para resolvê-las.

Antes da realização das entrevistas, cada participante assinou o Termo de Consentimento Livre e Esclarecido, sendo-Ihe garantido o direito ao anonimato e à confidencialidade das informações. As entrevistas foram gravadas em fita K-7, após autorização verbal do entrevistado. Os profissionais entrevistados foram identificados com sua função na Unidade, seguido da primeira letra do nome e do número da unidade a qual pertencem (Ex.: ACS R - USF 2).

A técnica de observação participante seguiu um roteiro elaborado pelas autoras que contemplava aspectos quanto às instruções para preenchimento de fichas de coletas de dados e relatório de consolidação dos dados. Todas as informações foram registradas em um diário de campo. A coleta de dados foi realizada no período de junho a outubro de 2009, com duração de 20 dias em cada unidade. Os dados obtidos foram tratados e analisados através da técnica de análise temática, segundo Minayo ${ }^{(11)}$.

O presente estudo é parte de um projeto matricial intitulado Atuação da enfermagem frente às necessidades emergentes na estratégia Saúde da Família no Município de Cuiabá-MT - desenvolvido pelo Grupo de Pesquisa Projeto Argos da Universidade Federal de Mato Grosso (UFMT), financiado pela Fundação de Amparo à Pesquisa do Estado de Mato Grosso (FAPEMAT), submetido ao Comitê de Ética em Pesquisa do Hospital Universitário Júlio Muller e aprovado em 04/02/09 com Parecer $n^{\circ}$ 708/CEP- HUJM/09.

\section{RESULTADOS E DISCUSSÃO}

\section{Reconhecimento de cada instrumento de coleta de dados do SIAB}

No que diz respeito à identificação das fichas e relatórios do SIAB pelos ACS, a maioria deles relatou conhecer somente das fichas $A$ e $B$ do SIAB, sendo esta última para acompanhamento das áreas estratégicas da ESF: gestantes e agravos prioritários (hipertensão, diabetes, tuberculose e hanseníase).

Poucos ACS referiram conhecimento acerca da ficha $C$ (acompanhamento da criança) e apenas uma ACS mencionou a ficha $D$, que é de responsabilidade de todos os membros da equipe, deixando, entretanto, de citar a ficha $B$.

Apenas os agentes da ESF 2 referiram conhecer o relatório SSA2, que deve estar em posse do ACS, o que pode indicar que os ACS da equipe 1 não reconhecem esse relatório como ferramenta do SIAB.

Vale ressaltar, que alguns relatos mostraram que os ACS também têm dificuldades em nomear algumas fichas, confundindo-as. Além da dificuldade em identificar as fichas, tampouco conseguem descrevê-las.
Na literatura disponível sobre o SIAB não foram encontrados estudos que discutiam o reconhecimento das fichas por parte dos profissionais que as utilizam. Assim, além de inéditos, esses achados são importantes a medida em que remetem à necessidade de educação permanente para estes profissionais, bem como põem em questão a qualidade do Curso Introdutório para o trabalho com saúde da família que deve ser, obrigatoriamente, oferecido a esses profissionais.

Os ACS relataram suas experiências em relação ao curso introdutório.

Não. Eu fui ter o introdutório só dois anos depois que eu já era agente de saúde. Então eu tive que fazer mesmo com as outras agentes que foram ensinando, com a enfermeira na época que era outra enfermeira e que foi ensinando também. (ACS L - USF 1)

Na verdade, no introdutório essas fichas foram apresentadas, explicadas só. (ACS E - USF 1)

Tais relatos demonstram que o processo de qualificação do ACS ainda é desestruturado, fragmentado e, na maioria das vezes, insuficiente para desenvolver as competências necessárias para o desempenho adequado de suas funções, bem mais complexas e abrangentes após a implantação da ESF, como também aponta Tomaz ${ }^{(12)}$.

O Treinamento Introdutório em Saúde da Família visa discutir os princípios e diretrizes do SUS e da ESF, instrumentalizando as equipes para a organização inicial de seu processo de trabalho. Neste treinamento, os ACS devem ser capacitados para analisar a situação saúde de sua área de abrangência, por meio da utilização das fichas do SIAB que devem ser utilizadas para a identificação dos problemas e potencialidades existentes. O Curso visa ainda capacitar os profissionais para compreender o uso dos indicadores do SIAB no monitoramento e na avaliação das atividades desenvolvidas para que ofereçam suporte ao processo decisório da USF ${ }^{(13)}$. Nesse sentido, o reconhecimento de cada instrumento/ficha que o profissional irá manusear no seu cotidiano de trabalho com o SIAB constitui-se em primeiro e indispensável conteúdo a ser disponibilizado aos ACS no Curso que os preparam para iniciar o trabalho na ESF, uma vez que sem essa devida aproximação o preenchimento adequado das fichas poderá ser comprometido.

\section{Preenchimento das fichas: dificuldades e dúvidas}

Em relação à ficha $A$, não foram referidas dúvidas ou dificuldades no preenchimento pelos ACS que participaram deste estudo. Entretanto, em relação a outras fichas, diversas dúvidas foram apresentadas.

Vários ACS relataram não ter dificuldades no preenchimento da ficha $\mathrm{B}$ de acompanhamento de tuberculose pelo fato de não estarem acompanhando usuários com esta patologia naquele momento. No entanto, alguns referiram dúvidas sobre o que seriam as reações indesejáveis dos medicamentos e como explicá-las à clientela. Outro fator gerador de dúvida diz respeito à variável relacionada ao comunicante da pessoa 
com tuberculose, o que pode ser evidenciado pelas falas que seguem.

A ficha de TB eu tive um TB só, então eu tenho algumas dificuldades, tem algumas coisas aí que eu não sei. O que eu conversei com a enfermeira sobre isso, ela me explicou alguma coisa, mas assim um TB só não deu e foi rápido também, não deu pra pegar muito a ficha de TB. Eu não sei se o comunicante é todo mundo que mora na casa e as reações indesejáveis quais são. (ACS R - USF 2)

Bom, essa aqui também é colada no meu caderno, a ficha, né. Então, a informação daqui tem todas, só assim, essas reações indesejáveis que eu tenho um pouco de dúvida, né, no caso pra explicar pro paciente, assim quando ele pergunta alguma coisa. Aí a gente manda pra unidade, pois tenho um pouco de dúvida. O resto não, exames, em relação a data, como que tem que ser feito, a gente fez um curso, então a gente tem bastante informação. (ACS L - USF 1)

No que diz respeito à ficha $B$ de acompanhamento de hipertensos houve diferença entre as unidades devido à falta de fichas impressas na primeira UBS em estudo. Nesta, as agentes tinham que reproduzir as informações das fichas em um caderno utilizado para substituir os formulários impressos. No entanto, essas fichas não eram reproduzidas integralmente no caderno, faltando algumas informações, como dieta e exercícios físicos.

Não tenho dúvida na ficha. A gente só pergunta os dados que tem ali, se faz dieta, se tomou alguma medicação, hipertenso sempre toma, né. No meu caderno tem as mesmas informações da ficha, mas falta se faz dieta e exercício físico. Algumas informações eu pego das fichas e do caderno das meninas para colocar no meu caderno. No caderno a gente coloca toda a medicação que o paciente toma, na ficha do SIAB não tem espaço para colocar a medicação. (ACS N - USF 1)

$\mathrm{Na}$ Unidade onde os ACS tinham as fichas disponíveis, não relataram dificuldades ou dúvidas, mas foram feitas observações em relação a essas fichas que poderiam melhorar/ aprimorar o trabalho. Trata-se, por exemplo, do espaço restrito para as anotações da visita e falta de espaço colocar a data de realização, pois, eventualmente, são realizadas mais de uma visita ao mês para o usuário hipertenso. Essa questão acaba por proporcionar certa dificuldade aos trabalhadores no que diz respeito à organização ou agendamento dessas visitas e, às vezes, o profissional não faz os registros necessários.

Isto envolve também outro problema no trabalho dos ACS: na maioria das vezes, o usuário não possui o cartão do hipertenso, onde são registradas as datas de consultas, o valor da pressão arterial e os medicamentos em uso, fazendo com que os ACS tenham que lançar mão do prontuário do usuário para obter essas informações ou simplesmente ignorá-las.

Assim, a gente costuma olhar quando eles vêm na consulta também. A gente costuma olhar aqui para poder pegar a pressão do dia da consulta e a consulta também, porque na ficha tem o dia da consulta deles, né. Então tem que olhar no prontuário, porque é assim né, eles consultam, descem e já marcam o retorno da próxima consulta, então a gente não fica nem sabendo que dia... Então tem de ir direto olhar no prontuário para ver o dia que consultou, a pressão... Quando passa na visita domiciliar que eles têm em mão a receita, o cartãozinho da pressão, então a gente faz anotação na casa mesmo. Mas quando eles falam: - Eu não sei onde est, está difícil....daí a gente deixa pra olhar na unidade, retiramos os dados aqui. (ACS E - USF 2)

Com relação à ficha $\mathrm{B}$ de acompanhamento de Diabetes, os ACS não relataram dúvidas quanto ao preenchimento, apenas sugeriram algumas informações que poderiam ser acrescentadas, como data da visita e valores da glicemia e da pressão arterial obtidos nas consultas.

Na unidade 1, que não dispunha de fichas impressas, os agentes tinham que usar cadernos em que, geralmente, não constavam algumas informações (dieta e exercícios físicos) ou continham informações adicionais (dose do medicamento em uso e valor da glicemia).

Como aqui não tem mais ficha $B$ de diabético é feito no nosso caderno, mas nem toda informação que está aí na ficha $B$ tem no caderno, só são algumas, como no caso do diabético. Aí mesmo só tem a glicemia, né, que a gente coloca, esses outros... não tem. A dieta também não é colocada no nosso caderno, exercício físico, né. A gente coloca o uso da insulina, se toma medicação, a data da consulta. (ACS L - USF 1)

Bom, tem algumas coisas que eu não conheço... Esse toma hipoglicemiante oral né, a gente pergunta se toma algum medicamento, mas como eu não tenho paciente que usa insulina, ainda eu não tive essa experiência. Aqui está faltando, a meu ver, os dados da glicemia, pra gente estar anotando. (ACS I - USF 2)

A ficha B de acompanhamento de Hanseníase não suscitou dúvidas em nenhum dos ACS que participaram deste estudo e a maioria referiu não ter ou não ter tido usuários com esta patologia em sua área de abrangência. Surgiram, porém, alguns questionamentos sobre a dose supervisionada e a vacina BCG para os comunicantes.

Não, nenhuma [dúvida]. No momento eu não tenho nenhum paciente, mas já tive vários. No começo foi difícil de entender o que significava a última dose supervisionada, mas agora já passou. (ACS N - USF 2)

Não. A minha dificuldade com eles é aprender o nome da medicação, que ainda não sei direito. Mas ta aí uma coisa que eu descobri agora, que você havia me falado, que os comunicantes tomam BCG, isso eu não sabia. (ACS I - USF 2)

A ficha B de acompanhamento de gestantes, por outro lado, acarreta muitas dúvidas/dificuldades para os ACS coletarem os 
dados. Eles expressaram desconhecimento relativo a termos presentes nas fichas, principalmente a identificação dos fatores de risco, como edema, natimorto, aborto e estado nutricional, sendo este também um dos resultados encontrados no estudo de Silva e Laprega ${ }^{(14)}$. Isto, por sua vez, leva muitos deles a não completar todos os dados da ficha, configurando um problema no repasse das informações para o SIAB informatizado. Outra queixa que voltou a ser citada foi a falta da data da visita do agente.

Sempre tem [dúvidas], é porque é a mais complicada que eu acho, a tipo natimorto, aborto, há... edema, essas coisas que eu tenho um pouquinho assim... (ACS E - USF 1)

A ficha $B$ também não tem nada assim de dificuldade, porque como eu já falei, elas são bem esclarecedoras, né. Na ficha, todos os dados são bem explicados, são todos os fatores que a gente já trabalha com eles todo o dia, né. A gente preenche o DPP, o DUM, pra você colocar se está nutrida ou desnutrida no mês e a data da consulta, né. $A$ gente colhe só esses dados. Esses fatores de risco que estão aqui, como natimorto, a gente não preenche. NV eu acho que é o número de nascidos vivos e $N M$ e $A B$ não consigo decifrar, não. (ACS M - USF 2)

Bom, o preenchimento da ficha tem alguma coisa aí... Esse natimorto, aborto, a questão dessas semanas que eu ainda não gravei... Mas isso são dificuldades minhas, porque a pessoa que tem conhecimento não vai ter problema pra preencher. Eu costumo preencher quando a pessoa sabe a data da última menstruação, data provável de parto, as vacinas quando tem demonstradas. Agora, eu não preencho a parte de mês de gestação, dado nutricional e fatores de risco, não sei o que é edema, sei o que é diabetes, pressão alta. $O$ edema se é o resultado de alguma queda... (ACS I - USF 2)

A ficha $C$ é preenchida com base nos dados do cartão da criança. Em relação a ela, os ACS da Unidade de Saúde 1 não relataram dúvidas relacionadas às vacinas, somente em relação à curva de peso do cartão da criança.

As vacinas não tenho dúvida, mas sobre esse negócio do peso pra marcar no cartão de vacina, às vezes eu tenho alguma dúvida sim, do percentual. (ACS T - USF 1)

Já na Unidade 2, as vacinas foram o alvo das dúvidas por parte dos ACS no início de suas atividades com Saúde da Família, mas no momento foram superadas. Quanto à curva de peso das crianças, nada foi mencionado.

Eu tive muita dificuldade nas vacinas, porque são muitas as vacinas e eu não tenho conhecimento de vacinas, né, e de vacinas ninguém me explicou profundo pra mim entender melhor, eu tenho muita dificuldades nas vacinas. (ACS $M-U S F$ 2)

Ainda sobre a ficha $\mathrm{C}$, as observações possibilitaram verificar que alguns termos também não estavam claros para os agentes, como a nomenclatura de algumas vacinas (tetravalente, por exemplo) e a sigla VAS (vias aéreas superiores).

Em relação ao preenchimento de todas estas fichas, vale ressaltar um agravante que interfere diretamente no trabalho dos ACS da USF 1: a falta de fichas impressas e a conseqüente necessidade da utilização de cadernos para a coleta dos dados junto à comunidade. Podemos perceber em muitos dos excertos acima que os cadernos já foram incorporados no cotidiano de trabalho desses agentes. Eles procuram reproduzir as informações das fichas nestes cadernos, contudo retiram dados que desconhecem ou julgam que não são importantes, acrescentando dados que acham necessários.

Uma das ACS revela que as anotações dos cadernos são mais completas que a própria ficha do SIAB. Outras, no entanto, referem que as informações que utilizam para a coleta de dados no caderno são diferentes as fichas do SIAB e/ou faltando informações das fichas no caderno. (Diário de campo USF 1)

A falta de material gera uma demanda extra de trabalho aos ACS desta unidade, que, para não interromper suas atividades, buscam outros meios para desenvolver suas práticas.

Com base nas mudanças que os ACS afirmam fazer em seus cadernos na transcrição das fichas, é possível considerar que ocorre a busca de adequação do instrumento de coleta de dados à realidade local, contemplando suas peculiaridades e negando um modelo de coleta de dados rígido e universal. Tais mudanças, potencialmente, poderiam subsidiar a reformulação dessas fichas e relatórios de acordo com as reais necessidades dos trabalhadores e da comunidade. Sobre isto, Freitas e Pinto afirmam que a elaboração do SIAB com visão nacional não enfoca as peculiaridades regionais, prejudicando a obtenção de dados importantes para a programação local ${ }^{(15)}$.

O agente é um morador da comunidade onde trabalha e o levantamento de dados e a produção da informação ocorrem em contextos de relações contínuas e recontextualização da realidade das famílias, o que relativiza a existência de uma objetividade absoluta na captação dos dados. Ao contrário, a subjetividade está presente na história subjacente à informação, quantitativa ou qualitativa, com a qual a equipe trabalha. Tal fato é muito importante no trabalho do PSF, pois a subjetividade do agente possibilita que se coletem dados/informações que os instrumentos tradicionais muitas vezes não permitem ${ }^{(4)}$.

Um estudo que analisou o SIAB como ferramenta da gestão em saúde concluiu que há possibilidades de readequar essa ferramenta para que sua utilidade seja ampliada, agilizando assim a tomada de decisão em processos de promoção e educação em saúde, bem como nos cuidados dispensados na atenção regionalizada ${ }^{(16)}$.

Na Unidade 2, que dispõe dos impressos de fichas e relatórios, os ACS relataram o não preenchimento de alguns dados, reafirmando que essas fichas não consideram a realidade local e precisariam ser reformuladas.

Geralmente o que a gente não costuma mesmo usar é o seguimento, o município, não preenche os dados todos, 
geralmente é o endereço, o número da família e a microárea, nem a data do cadastro da família, a gente não tá colocando. É uma falha mesmo nossa, não é que não está entendendo a ficha, é que a gente acostumou a não colocar. Também na ficha A de cadastro, eu acho que meio de transporte, comunicação, as pessoas não gostam muito de falar não, isso não tem nada a ver com a saúde, é muito pessoal. [...] Eu não costumo preencher na ficha o estado nutricional e os fatores de risco, só menores de vinte anos. Nem data da consulta do puerpério a gente não ta marcando. (ACS N - USF 2)

Os excertos mostram negligência por parte dos profissionais frente a dados importantes para o processo de consolidação das informações e conseqüente planejamento, avaliação e monitoramento das ações da unidade. Mas, por outro lado, pode evidenciar despreparo ou desconhecimento sobre a necessidade do preenchimento total das fichas e descrédito quanto a real utilidade/aplicação dos dados que coletam. Isto pode ser justificado pelo seguinte relato de observação.

A ACS relatou que o SIAB (referindo-se ao software) não utiliza muitas informações das fichas, dizendo que o programa só pede número de gestantes, hipertensos, diabéticos, com hanseníase e tuberculose cadastrados e acompanhados e as outras informações existentes nas fichas ficam somente no "papel". (Diário de campo USF 1)

Um estudo que analisou a percepção de uma equipe de saúde da família sobre a utilização SIAB no município de Franca, $\mathrm{SP}^{(15)}$ concluiu que a alimentação inadequada dos Sistemas de Informação em Saúde (SIS) leva a inserção de dados não compatíveis com a realidade local, prejudicando os processos de planejamento, execução e avaliação das práticas de saúde.

Diante das dúvidas e dificuldades, os ACS fazem apontamentos em relação às informações das fichas. O principal diz respeito às doenças mentais. A observação das atividades nas unidades e relatos dos agentes evidenciou expressiva necessidade destas patologias serem contempladas nas fichas. Tal assertiva fica clara diante do seguinte relato de observação:

A ACS " $L$ " relatou que gostaria que a pesquisa pudesse resolver alguns problemas em relação ao SIAB, dando exemplo que em sua microárea há muitas pessoas com problemas mentais e no SIAB não consta da lista de doenças referidas essa morbidade. Para tal, a ACS tem um caderno próprio onde todas as informações sobre seus pacientes são registradas e SIC da mesma é bem mais completo que o SIAB. (Diário de campo USF 1)

Outras informações como a classificação NIC I para o câncer de colo uterino, aleitamento artificial, fatores que podem impedir a amamentação (como a infecção da mãe pelo HIV), patologias como sinusite, bronquite, asma, além do uso do fumo por pacientes com tuberculose, também foram informações importantes que os agentes relataram não constar nas fichas do SIAB, dentre outras.
Assim, falta alguma coisa né... Devia ter mais informação sobre o tipo de doenças, que não tem espaço pra colocar, tem as mais importantes que são diabetes, hipertensão, hanseníase... As outras não têm espaço. (ACS T - USF 1)

Eu acho que falta, tipo assim, nós temos muito casos de dependentes químicos, né e na ficha $A$ nós não temos como estar colocando essa informação. A parte também de deficiente visual também não tem onde estar colocando esses dados. (ACS A - USF 1)

Silva e Laprega ${ }^{(14)}$ também mencionaram que uma característica negativa bastante ressaltada em seu estudo, assim como pelos ACS, é o número limitado de doenças ou condições referidas codificadas na ficha $A$, os quais nem sempre refletem a realidade local. Como exemplo, foi citada a impossibilidade de registrar doenças como depressão e AIDS, em detrimento de outras codificáveis pelo SIAB, mas de menor prevalência ou até mesmo inexistentes para a maioria das equipes, como a malária.

\section{Resolução das dificuldades e dúvidas}

Os ACS entrevistados referiram ter enfrentado dificuldades no início das atividades na ESF, superadas com a orientação da enfermeira e colaboração dos demais ACS com experiência na ESF que os ajudaram no processo de compreensão das fichas/relatórios.

Bom, assim, no começo eu não tinha nenhuma informação, pelo menos eu não recebi nenhum curso de como preencher as fichas. Foi difícil, eu aprendi assim com outros Agentes de Saúde que foram passando informação pra gente como fazia, como preenchia. (ACS L - USF 1)

Quando eu tenho alguma dúvida eu peço para a enfermeira que ela explica, orienta e quando dá, ajuda no que ela pode. (ACS E - USF 1)

No estudo realizado por Silva e Laprega ${ }^{(14)}$, quanto às dúvidas que surgiam, os ACS informaram que procuram as enfermeiras no dia a dia de trabalho ou em espaços reservados durante a semana para a discussão de casos pertinentes às famílias.

Enquanto algumas ACS relataram não ter encontrado dificuldades em nenhum momento do trabalho, e outras demonstraram a convivência permanente com dificuldades em relação às fichas do SIAB.

Pra mim, a todo o momento eu tenho dificuldade, porque são muitos os dados, eu já tive dificuldades pra preencher. (ACS M - USF 2)

\section{CONSIDERAÇÕES FINAIS}

O SIAB é uma ferramenta fundamental ao trabalho na ESF. Tem como objetivo sistematizar todos os dados levantados junto à comunidade da área adscrita, otimizando o processo de trabalho da equipe. 
Considerando a importância do trabalho do ACS no levantamento de dados para alimentação do SIAB, o presente estudo possibilitou uma aproximação com sua vivência cotidiana e a identificação de situações-problema enfrentadas durante a execução de suas práticas relacionadas ao trabalho com esse sistema de informação.

Uma das limitações do estudo foi ter sido desenvolvido em apenas duas USF do município, o que se configura com uma limitação para a generalização dos resultados. Ainda assim, as análises realizadas permitiram identificar que os ACS, sujeitos desta pesquisa, apresentam dificuldades para identificar e nomear as fichas, bem como descrevê-las ou compreender um número considerável de variáveis/termos/patologias.

A identificação destas dificuldades pode contribuir com a efetivação da ESF, subsidiando os gestores do SUS no aprimoramento da estrutura das fichas/relatórios, adequando-os à realidade local das USF, por meio de acréscimo ou retirada de dados.

Outra possibilidade que se apresenta frente aos dados analisados está relacionada ao processo de educação permanente destes profissionais, que possibilitaria a melhoria do cotidiano de trabalho dos ACS, assim como de toda a equipe, e daria mais qualidade às informações geradas pelo SIAB.

\section{REFERÊNCIAS}

1. Brasil. Lei $n^{\circ} 11.350$, de 5 de outubro de 2006. Regulamenta o $\S 5^{\circ}$ do art. 198 da Constituição, dispõe sobre o aproveitamento de pessoal amparado pelo parágrafo único do art. 2o da Emenda Constitucional no 51, de 14 de fevereiro de 2006, e dá outras providências. Diário Oficial da União 05 out 2006

2. Ministério da Saúde [homepage na internet]. Descrição das competências profissionais do ACS. Brasília: Ministério da Saúde; 2010 [acesso em 29 abri 2010]. Disponível em: http://portal.saude.gov.br/portal/sgtes/visualizar texto.cfm?idtxt $=23095$.

3. Ministério da Saúde [homepage na internet]. O trabalho do Agente Comunitário de Saúde. Brasília: Ministério da Saúde; 2009 [acesso em 29 abr 2010]. Disponível em: http:// dab.saude.gov.br/docs/publicacoes/geral/guia_acs.pdf.

4. Nichiata, LYI; Fracolli LA. O Sistema de Informação de Atenção Básica (SIAB) como um instrumento de trabalho da equipe no Programa de Saúde da Família: a especificidade do enfermeiro. In: Instituto para o Desenvolvimento da Saúde; USP; MS, organizadores. Manual de Enfermagem. Programa de Saúde da Família. São Paulo: Ministério da Saúde; 2001.

5. Hildebrand SM; Shimizu HE. Percepção do agente comunitário sobre o Programa Família Saudável. Rev Bras Enferm 2008;61(3):319-24.

6. Coriolano MWL e Lima LS. Grupos Focais com Agentes Comunitários de Saúde: subsídios para entendimento destes atores sociais. Rev Enferm UERJ 2010;18(1):92-6.

7. Oliveira QC. SIAB: do processo de produção de dados à análise das informações em duas equipes de saúde da família no município de Cuiabá/MT. Cuiabá. Dissertação [Mestrado em Enfermagem] - Universidade Federal de Mato Grosso; 2010

8. Rodrigues CG, Rodrigues FG, Wong LR, Perpétuo IHO. Os sistemas de informação em saúde: do processo de trabalho à geração dos dados em Minas Gerais. CEDEPLAR/UFMG [homepage na internet] [acesso em 10 maio 2010]. Disponível em: < cedeplar.ufmg.br/seminários > .

9. Ministério da Saúde [homepage na internet] Secretaria de Atenção à Saúde. Departamento de Atenção Básica. SIAB: manual do Sistema de Informação da Atenção Básica. Brasília: Ministério da Saúde; 2000a. [acesso em 19 jul 2010]. Disponível em: www.saude.gov.br/dab.

10. Ministério da Saúde [homepage na internet]. Manual do Agente Comunitário de Saúde. Brasília: Ministério da Saúde; 2009 [acesso em 29 abr 2010]. Disponível em: http://dab.saude.gov.br/docs/publicacoes/geral/manual_acs.pdf.

11. Minayo MCS. O desafio do conhecimento: pesquisa qualitativa em saúde. 9a ed. São Paulo: Hucitec; 2006.

12. Tomaz JBC. O agente comunitário de saúde não deve ser um "super-herói". Interface Comun Saúde Educ 2002; 6(10):75-94.

13. Ministério da Saúde [homepage na internet]. Departamento de Atenção Básica. Secretaria de Políticas de Saúde. Treinamento Introdutório. [Cadernos de Atenção Básica2] 2000 [acesso em 30 jan 2010]. Disponível em: http:// bvsms.saude.gov.br/bvs/publicacoes/cad 02treinamento. pdf.

14. Silva AS e Laprega MR. Avaliação crítica do Sistema de Informação da Atenção Básica (SIAB) e de sua implantação na região de Ribeirão Preto, São Paulo, Brasil. Cad Saúde Pública 2005; 21(6):1821-8.

15. Freitas FP, Pinto IC. Percepção da equipe de saúde da família sobre a utilização do sistema de informação da atenção básica - SIAB. Rev Latinoam Enferm 2005;13(4):547-54.

16. Bittar TO. Meneghim MC, Mialhe FL, Pereira AC, Fornazari DH. O Sistema de Informação da Atenção Básica como ferramenta da gestão em saúde. RFO UFP 2009;14(1):77-81. 